\title{
Evaluation of mold-enclosed shear bond strength between zirconia core and porcelain veneer
}

\author{
Kwang-Hyun SONG ${ }^{1 *}$, Yong-Woon $\mathrm{IM}^{2,3 *}$, Jung-Hwan LEE ${ }^{2,4}$, Jonghyuk $\mathrm{LEE}^{1}$ and Hae-Hyoung $\mathrm{LEE}^{2,4}$ \\ ${ }^{1}$ Department of Prosthodontics, College of Dentistry, Dankook University, Cheonan, Korea \\ ${ }^{2}$ Department of Biomaterials Science, College of Dentistry, Dankook University, Cheonan, Korea \\ ${ }^{3}$ Department of Dental Laboratory, Kyungdong University, Wonju, Korea \\ ${ }^{4}$ Institute of Tissue Regeneration Engineering, Dankook University, Cheonan, Korea \\ Corresponding author, Hae-Hyoung LEE; E-mail: haelee@dku.edu
}

\begin{abstract}
This study aimed to evaluate the mold-enclosed shear bond strength (ME-SBS) of zirconia to veneering porcelain with different surface treatments. Colored or uncolored zirconia coupons were either highly polished or airborne-particle abraded. The specimens were divided into groups with/without application of liner. Veneering porcelain was fired into an alumina ring mold on the zirconia coupons. The assembled specimens were subjected to the ME-SBS test. The mean ME-SBS for groups ranged from 7-10 MPa with no significant difference $(p>0.05)$. A three-way ANOVA showed that coloring and surface roughening of the zirconia specimen had no significant influence on the ME-SBS value, but liner application exhibited a significant effect with a minor decrease in the MESBS $(p=0.049)$. Surface treatments (coloring, airborne-particle abrasion, and liner application) were found to not cause a significant increase to the zirconia-porcelain bond strength. The application of zirconia liner had a slight negative influence on the ME-SBS results.
\end{abstract}

Keywords: Zirconia, Coloring, Airborne-particle abrasion, Liner application, Mold-enclosed shear bond strength

\section{INTRODUCTION}

With advances in the field of dental materials and technology, all-ceramic or metal-free toothcolored restorations have become a routine option in contemporary prosthodontic treatments. Among such restorative systems, zirconia ceramics are central to allceramic restorative systems, including multiunit fixed partial dentures, owing to their outstanding mechanical properties and dental CAD-CAM technologies ${ }^{1-3)}$. However, zirconia ceramics are pure white and highly opacity, making it difficult to mimic a natural tooth with an optimal shade using this material alone. Thus, to fabricate zirconia restorations with highly esthetics, it is necessary to apply veneering porcelains onto zirconia substrate by means of powder-slurry build-up or heatpressing ${ }^{4}$. An extrinsic or intrinsic coloring of zirconia core with a shade similar to dentin would possibly be help to improve the esthetics of zirconia restorations ${ }^{5}$.

However, chipping of the porcelain veneer from the zirconia core are often occurred in clinical applications and the most common failure in zirconia restoration when compared to metal-ceramic restorations. The initial incidence rate of chipping in zirconia restorations has been reported as generally $15-25 \%$ after $24-31$ month $^{6-8)}$. The incidence rate was decreased to $6 \%$ for 37 months lately, chipping was main hurdle for clinical success of zirconia-porcelain restorations ${ }^{9}$. There are many factors contributing to this chipping ${ }^{10)}$. Porcelain

\footnotetext{
*These authors are co-first authors.

Color figures can be viewed in the online issue, which is available at J-STAGE.

Received Sep 20, 2017: Accepted Dec 15, 2017

doi:10.4012/dmj.2017-339 JOI JST.JSTAGE/dmj/2017-339
}

chipping in all-ceramic restorations, including zirconiaporcelain systems, is caused by excessive tensile stress due to a thermal mismatch between the porcelain veneer and the zirconia core, inadequacies in the geometry of the framework design and/or core/veneer thickness ratio, an insufficient bond strength of the core-veneer combination, and so on ${ }^{6,11}$. To overcome these chippinginduced failures, a higher bonding strength between the zirconia core and veneer materials is essential because this bond constitutes the weakest part of a zirconia prostheses veneered with porcelain ${ }^{12}$.

Researchers have determined that the factors influencing the bond strength between zirconia and porcelain are chemical bonding, mechanical bonding relying on the surface roughness of zirconia, the wetting properties of porcelains, and the compressive stress acting on veneer layer due to difference in the thermal expansion coefficient ${ }^{13,14)}$. Among the various factors affecting the bond strength, airborne-particle abrasion and the application of a zirconia liner has been the subject of many studies with the goal of increasing the zirconia-porcelain bond strength, as these surface treatments are strongly recommended by manufacturers. However, studies addressing the effects of surface treatments on the bond strength have often produced conflicting results ${ }^{13-18)}$. For example, it has been indicated that roughening of the zirconia can increase the shear bond strength of veneering ceramic to zirconia ${ }^{16-18)}$. However, other studies have concluded that neither particle abrasion nor liner application increases the bond strength significantly ${ }^{13-15}$. Therefore, 
Table 1 Materials used in this study

\begin{tabular}{llcc}
\hline \multicolumn{1}{c}{ Materials } & \multicolumn{1}{c}{ Brand } & Manufacturer & Lot No. \\
\hline Zirconia & IPS e.max ZirCAD & N78026 \\
Coloring liquid & CL1 & Ivoclar Vivadent, Schaan, & R60559 \\
Liner & IPS e.max Ceram Zirliner & Liechtenstein & T42562 \\
Porcelain & IPS e.max Ceram Dentin (A2) & & S20293 \\
\hline
\end{tabular}

the influence of those surface treatments on the bond strength between zirconia core and veneering porcelain remains uncertain.

Although various test methods have been proposed to evaluate the bond strength between the core and veneer materials, micro- or macro-shear bond strength (SBS) tests have been most widely adopted by previous studies due to the simplicity of the sample preparation and the testing procedure. However, the conventional SBS test protocol has been criticized due to its stress localization and the non-uniform distribution of stresses in the interface between the adhesive and adherend surfaces ${ }^{19-22)}$. As an alternative, the mold-enclosed shear bond strength (ME-SBS) test has been proposed as a means of eliminating the uneven stress issue of the conventional SBS test ${ }^{23-25)}$. Previous studies have adopted the ME-SBS test to compare the bond strength between composite resin/cement materials and dental alloys ${ }^{24,26)}$. However, to the best of our knowledge, no studies have used the ME-SBS test method for investigating the ceramic-ceramic bond strength.

The goal of the present study is to evaluate the influences of the coloring, liner application, and airborne-particle abrasion of zirconia core on the bond strength between the zirconia ceramic and the veneering porcelain, using the ME-SBS test. In particular, the bond strength between the veneering porcelain and a highly polished zirconia surface was compared with that between a veneering porcelain and particle abraded zirconia. The null hypothesis of this study was that the surface treatments of zirconia, including coloring, roughening by particle abrasion, or the application of a zirconia liner have no influence on the ME-SBS between zirconia and porcelain ceramic.

\section{MATERIALS AND METHODS}

\section{Preparation of zirconia specimen and coloring}

A total of 80 presintered zirconia specimen coupons measuring $19 \mathrm{~mm}(\mathrm{~W}) \times 15 \mathrm{~mm}(\mathrm{~L}) \times 3 \mathrm{~mm}(\mathrm{H})$ were made by cutting commercial zirconia blanks intended for CADCAM (IPS e. max ZirCAD, Ivoclar Vivadent, Schaan, Liechtenstein) using a dental cast-cutting machine with a diamond disk (Cutter Plus, High Dental, Seoul, Korea). To establish the baseline condition, the surfaces of all the sample coupons were wet-ground with \#180 SiC paper (Struers, Ballerup, Denmark), ultrasonicated in distilled water for $10 \mathrm{~min}$, and then dried. The prepared zirconia coupons were divided into colored and uncolored groups $(n=40)$. Forty specimens of the colored group were immersed in coloring liquid (CL1, Ivoclar Vivadent) for $2 \mathrm{~min}$, washed in water, and then dried to make the colored specimens. Then, all the specimen coupons were subjected to a final sintering process in the furnace intended for ZirCAD (Programat S1, Ivoclar Vivadent) according to the manufacturer's instructions. Table 1 shows the materials used in the present study.

\section{Surface treatments and zirconia liner application}

All the zirconia specimens (both colored and uncolored) were again separated into two groups, namely, highpolished and airborne-particle abraded groups $(n=20)$. To produce a roughened zirconia surface, a particle blaster (Basic, Renfert, Hilzingen, Germany) and 110$\mu \mathrm{m} \mathrm{Al}_{2} \mathrm{O}_{3}$ particles (Renfert) were used, with the blaster set to a distance of $10 \mathrm{~mm}$, an angle of $45^{\circ}$, and a pressure of 4 bar, for $10 \mathrm{~s}$. For the highly polished group, the zirconia coupons were ground using a horizontal grinding machine (HRG 150, AM Technology, Ansan, Korea) and then polished sequentially using a lapping machine (Okamoto, Annaka, Japan) with 6, 3, and then $1-\mu \mathrm{m}$ diamond polishing slurries. Then, ultrasound cleansing was performed with acetone for $10 \mathrm{~min}$. After the surface treatments, the surface roughness $\left(R_{a}\right)$ of each group was determined using a surface roughness tester (SJ-400, Mitutoyo, Tokyo, Japan) operating at a speed of $0.5 \mathrm{~mm} / \mathrm{s}$ with a $4 \mathrm{~mm}$ scan. Three tests were performed on each surface $(n=6)$.

Each of the surface treatment groups were further divided into 2 groups, that is, with or without the application of a zirconia liner (IPS e.max Ceram Zirliner, Ivoclar Vivadent) $(n=10)$. A thin silicone index with a hole (4 $\mathrm{mm}$ diameter) was used to position the Zirliner in the center of the specimens. The liner was first applied to the indexed area using a brush and then fired independently according to the manufacturer's instructions. After the first firing, the Zirliner was reapplied to compensate for the shrinkage that occurs in sintering and then fired again.

Preparation of zirconia-porcelain mold-enclosed specimens and the shear bond test

To prepare zirconia-porcelain ME-SBS specimen, an alumina ring mold (with a material thickness of 1.0 $\mathrm{mm}$, a height of $5 \mathrm{~mm}$, and an inner diameter of 4.0 $\mathrm{mm}$ ) was used to enclose the veneering porcelain (IPS e.max Ceram Dentin A2, Ivoclar Vivadent), bonded to the zirconia core ceramic. First, porcelain mixed with 
the manufacturer's liquid was built-up into the alumina ring mold to a depth of about $1 \mathrm{~mm}$ using an ultrasonic vibrator (Ceramosonic, Shofu, Kyoto, Japan) and then fired without the ring mold. After the first firing, the alumina ring was repositioned on the specimen disks and veneer porcelain was added to compensate for the porcelain shrinkage, up to a depth of $2 \mathrm{~mm}$. Then, the specimens were fired twice with the alumina ring. A total of five firing procedures (two liner and three dentin porcelain firings) were performed according to the manufacturer's instructions to simulate the routine laboratory process for fabricating dental zirconia prosthesis. After firing, a shiny, glassy surface was observed on the surface of the porcelain, indicating that the firing was satisfactory (Fig. 1). The assembled zirconia-porcelain ME-SBS specimens were embedded into a self-cured acrylic resin (Quickcure, Alliedtech, Rancho Dominguez, CA, USA) using a cylindrical mold (diameter $30 \mathrm{~mm}$ and height $20 \mathrm{~mm}$ ). All specimens were stored in distilled water at a temperature of $37^{\circ} \mathrm{C}$ for 24 prior to the test.

The SBS test was performed using a metal apparatus conforming to ISO/TS 11405 (Dental Materials-Testing of adhesive to tooth structure) mounted in a universal test machine (Instron 3344, Instron, Norwood, MA, USA). The specimens were debonded using a hardened steel shear blade with an 8 - $\mathrm{mm}$ diameter hole with a blunt end $(1 \mathrm{~mm})$ at a crosshead speed of $1 \mathrm{~mm} / \mathrm{min}$ (Fig. 1). The ME-SBS value (MPa) was calculated by dividing the maximum debonding load $(\mathrm{N})$ with the crosssection area $\left(12.6 \mathrm{~mm}^{2}\right)$ of the alumina ring mold. The debonded surfaces of specimens were analyzed using a stereomicroscope to identify the failure mode (adhesive or cohesive) and selected samples are observed using scanning electron microscope (S-3000H, Hitachi, Tokyo, Japan).

\section{Statistical analysis}

The mean SBS values were obtained by testing 10 specimens from each group. Three-way ANOVA was performed to examine the effect of coloring, surface treatment, liner application, and their interactions, on the SBS. The mean SBS values were statistically analyzed using one-way analysis of variance (ANOVA) with Tukey's post hoc test (SPSS 22.0; SPSS, Chicago, IL, USA). The surface roughness was analyzed by an independent $t$-test $(\alpha=0.05)$. A value of $p<0.05$ was

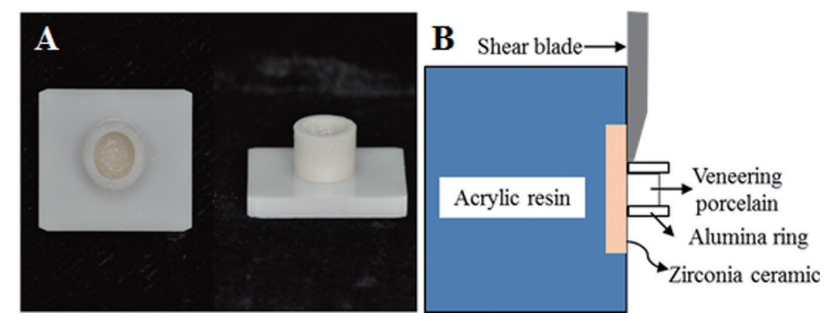

Fig. 1 Mold-enclosed zirconia-porcelain SBS specimen (A). Schematic diagram of test setup (B). considered to be significant.

\section{RESULTS}

The values obtained for the surface roughness of the zirconia specimen are shown in Fig. 2. The machine polishing procedure of zirconia produced a mirror surface with a very low mean $R_{\mathrm{a}}(\sim 0.02 \mu \mathrm{m})$, compared to the alumina-particle blasting treatment $(0.61-0.64$ $\mu \mathrm{m})$. However, there were no differences in the mean $R_{a}$ between colored and uncolored specimens $(p=0.81)$.

An ME-SBS test of the zirconia-porcelain system was successfully conducted in the present study. All the specimens ultimately failed with the detachment of the porcelain-filled alumina ring mold. SEM images of the debonded area are shown in Fig. 3. Those specimens without the zirconia liner exhibited interface (adhesive) failures between the zirconia and porcelain, but some porcelain components remained on both the alumina blasted (Fig. 3A) and highly polished zirconia surfaces (Fig. 3B). However, the particle abrasion specimens with the zirconia liner exhibited a cohesive failure in the veneer porcelain (Fig. 3C) while the polished specimens with the liner exhibited a combination of adhesive and cohesive failures (Fig. 3D).

Figure 4 shows the mean ME-SBS values between a zirconia core and a porcelain veneer, depending on the surface treatments (coloring and air abrasion) and whether a liner is applied. The mean ME-SBS value was highest in that group which was colored and aluminablasted but which had no zirconia liner. In this case, the value was 9.6 $\pm 2.0 \mathrm{MPa}$. Meanwhile, group with liner, which was also uncolored and polished, marked the lowest bond strength value 7.0 $1.9 \mathrm{MPa}$. However, the one-way ANOVA results showed no statistically significant difference for the mean ME-SBS value $(p=0.130)$. A three-way ANOVA showed that coloring of the zirconia core $(p=0.058)$ and surface roughening $(p=0.584)$ had no statistically significant influence on

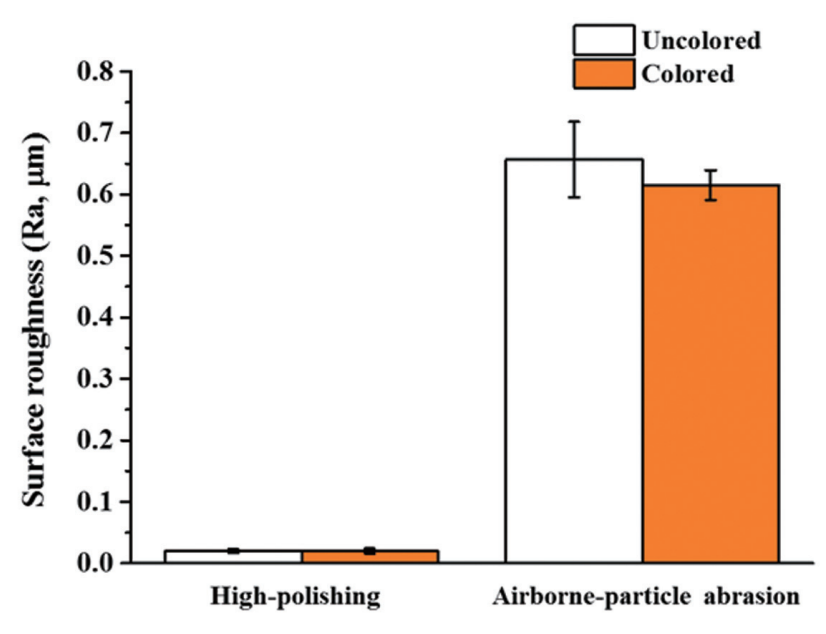

Fig. 2 Surface roughness $\left(R_{\mathrm{a}}\right)$ values of zirconia specimens. 


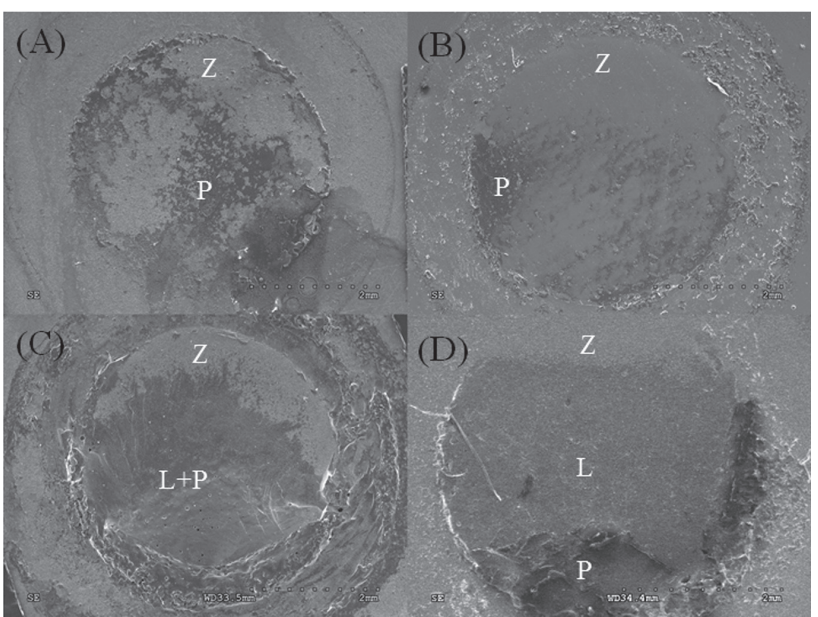

Fig. 3 Typical SEM images of debonded surface of zirconia-porcelain specimens: A, airborne-particle abrasion with no liner; B, high-polishing with no liner; C, airborne-particle abrasion with liner; D, high-polishing with liner. Z (zirconia), P (porcelain), and L (liner).

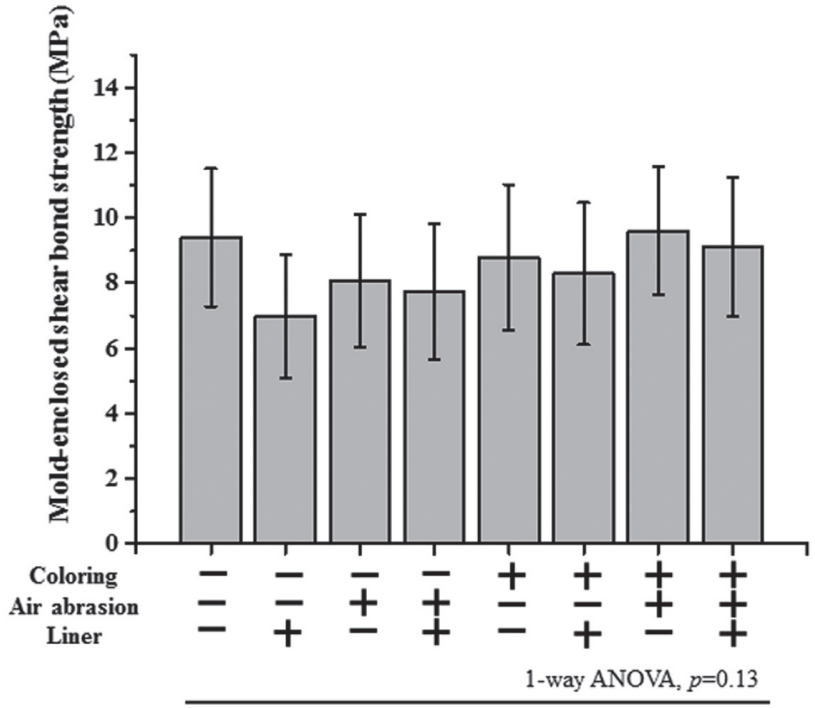

Fig. 4 Comparison of ME-SBS of groups according to surface treatments.

Table 2 Results of three-way ANOVA for comparison of mold-enclosed shear bond strength with coloring, roughening, application of liner, and their interactions

\begin{tabular}{lccccc}
\hline \multicolumn{1}{c}{ Source } & Sum of Squares & $d f$ & Mean Square & F & $p$ \\
\hline Coloring & 16.038 & 1 & 16.038 & 3.697 & 0.058 \\
Roughening & 1.312 & 1 & 1.312 & 0.303 & 0.584 \\
Application of liner & 17.392 & 1 & 17.392 & 4.009 & 0.049 \\
Coloring $\times$ Roughening & 6.084 & 1 & 6.084 & 1.403 & 0.240 \\
Coloring $\times$ Liner & 3.639 & 1 & 3.639 & 0.839 & 0.363 \\
Roughening $\times$ Liner & 5.352 & 1 & 5.352 & 1.234 & 0.270 \\
Coloring $\times$ Roughening $\times$ Liner & 5.510 & 1 & 5.510 & 1.270 & 0.263 \\
Error & 312.320 & 72 & 4.338 & - & - \\
Total & $6,145.348$ & 80 & - & - & - \\
\hline
\end{tabular}

the SBS of the zirconia core and porcelain veneer (Table 2). However, the application of a liner had a statistically significant influence on the ME-SBS value $(p=0.049)$. All the interactions were insignificant $(p>0.05)$ (Table 2$)$.

\section{DISCUSSION}

The use of the ME-SBS test was suggested to provide a more evenly distributed interfacial stress by enclosing the adherent in a mold ${ }^{23)}$. Jin et al. demonstrated, using 3D finite element analysis, that the ME-SBS test setup was suitable than the conventional SBS test method for evaluating SBS in adherend-composite resin bond models ${ }^{25}$. It was previously demonstrated that the MESBS test could provide a more valid result in metal- cement bonding joints, relative to non-ME SBS tests ${ }^{24)}$. In the present study, a pure alumina ceramic ring with a significantly higher elastic modulus $(\sim 370 \mathrm{GPa})$ than that of the porcelain veneer $(\sim 70 \mathrm{GPa})^{27)}$, was used as the mold material so that the exerted shear force could be distributed over the entire zirconia-porcelain interface during the shear bond test.

Based on the three-way ANOVA test results, it can be said that the null hypothesis in that the surface treatments (coloring and air abrasion) applied to the zirconia core do not influence the ME-SBS values with a porcelain veneer was proven (Table 2). Only the application of a liner to the Zirconia resulted a slight decrease in the mean ME-SBS values with statistical significance $(p=0.049)$. 
The use of a zirconia liner is recommended by manufacturers for masking the innate white color and opaqueness of a zirconia core while increasing the bond strength of a porcelain veneer. A positive effect of using a liner on the bond strength can be expected in a limited range of combinations of zirconia and layered porcelain. However, the results of most previous studies on the use of a liner have actually exhibited a negative or no effect on the zirconia-porcelain bond strength ${ }^{13,15,16,28-30)}$, as shown in this study. In the present study, liner layers were observed to remain on the zirconia surface after the debonding test (Fig. 3C). This indicates that a debonding failure could be initiated in the liner-porcelain interface, rather than in the zirconia-liner interface ${ }^{29}$.

The coloring of the zirconia ceramic may affect the strength of the bond with a porcelain veneer due to the effects of the coloring agents (which are metallic oxides). The present study found that there is little difference in the SBS value of colored and uncolored zirconia, with only small variations arising from the surface coloring, which is in agreement with the results of previous studies ${ }^{11,31}$. However, the interpretation of these results should be cautious because coloring treatments of some zirconia ceramics can compromise their mechanical properties depending on the composition of the coloring oxides $^{32-34)}$, possibly resulting in a decrease in the bond strength with the veneering porcelain.

On the other hand, previous studies have produced inconsistent results regarding the effect of surface roughening on the zirconia-porcelain bond strength. Several studies reported that surface roughening of the zirconia by airborne-particle abrasion had a positive effect on the conventional SBS value ${ }^{16-18,35)}$. However, other studies found that the air abrasion had no effect on the SBS value ${ }^{6,13,30)}$, in line with the results of the present study. Moreover, the present study found that even those zirconia surfaces that had been polished to a mirror finish $\left(\mathrm{R}_{\mathrm{a}}, 0.02 \mu \mathrm{m}\right)$ produced a zirconia-porcelain bond strength that was comparable to that with a particle-abraded zirconia surface $\left(R_{a}, 0.64 \mu \mathrm{m}\right)$.

It is notable that the bond strengths between zirconia and porcelain can differ depending on the test method employed ${ }^{6}$. For example, those previous studies reporting a positive effect in the zirconia-porcelain bond strength by an air abrasion treatment have used the conventional SBS test ${ }^{16-18)}$, with no mold-enclosing of the porcelain. However, other studies used either the Schmitz-Schulmeyer test ${ }^{6,13,36)}$ or Schwickerath crackinitiation test ${ }^{30)}$ have concluded that airborne-particle abrasion had little effect on increasing the SBS between zirconia and the veneer porcelain.

The mean conventional SBS values reported for zirconia-porcelain combinations in the literature covered a range of $17-55 \mathrm{MPa}^{4,16,37-44)}$. However, the mean MESBS values obtained in the present study ranged from 7-10 $\mathrm{MPa}$, which are much lower than those for conventional SBS. The relatively wide variation in the conventional SBS values could be attributed to the effects of stress concentration and non-uniform stress resulting from a conventional shear test without mold enclosing. The ME-SBS value determined by the present study exhibited a similar result to that of the SchmitzSchulmeyer SBS (9-12 MPa) obtained for several zirconia-porcelain systems in a previous study ${ }^{6}$. The Schmitz-Schulmeyer method has been assumed to be a reliable test setup for metal-ceramic systems ${ }^{45}$. Even with this test setup, however, a large difference in the Schmitz-Schulmeyer SBS values has been found for zirconia-porcelain systems ${ }^{36,46)}$.

Currently, no single bond strength test has been identified as being a de-facto standard for ceramic-ceramic systems. Although the Schwickerath crack-initiation test was adopted by the ISO 9693-2:2016 standard for zirconia-porcelain systems ${ }^{47}$, very few studies have applied this standard to bond characterization. In the present study, the ME-SBS test was first applied to evaluate the effect of various surface treatments on the SBS of a zirconia-porcelain combination. Other variables should be further studied to demonstrate the validity of this test setup for dental ceramic-ceramic systems.

\section{CONCLUSION}

Within the design of this study, no surface treatment produced a significant increase in the zirconia-porcelain bond strength. It was found that coloring treatment and different surface roughness $\left(\mathrm{R}_{\mathrm{a}}, 0.02 \mu \mathrm{m} v s\right.$. $0.64 \mu \mathrm{m}$, of the zirconia ceramic do not have a significant effect on the zirconia-porcelain ME-SBS. The application of a zirconia liner has a slightly negative effect on the MESBS value.

\section{ACKNOWLEDGMENTS}

This research was supported by Basic Science Research Program through the National Research Foundation of Korea (NRF) funded by the Ministry of Science, ICT and future planning (2015R1A2A2A01007567).

\section{REFERENCES}

1) Miyazaki T, Hotta $Y$, Kunii J, Kuriyama S, Tamaki $Y$. A review of dental CAD/CAM: current status and future perspectives from 20 years of experience. Dent Mater J 2009; 28: 44-56.

2) Raigrodski AJ, Hillstead MB, Meng GK, Chung KH. Survival and complications of zirconia-based fixed dental prostheses: a systematic review. J Prosthet Dent 2012; 107: 170-177.

3) Li RWK, Chow TW, Matinlinna JP. Ceramic dental biomaterials and CAD/CAM technology: State of the art. J Prosthodont Res 2014; 58: 208-216.

4) Ishibe M, Raigrodski AJ, Flinn BD, Chung KH, Spiekerman C, Winter RR. Shear bond strengths of pressed and layered veneering ceramics to high-noble alloy and zirconia cores. J Prosthet Dent 2011; 106: 29-37.

5) Sedda M, Vichi A, Carrabba M, Capperucci A, Louca C, Ferrari M. Influence of coloring procedure on flexural resistance of zirconia blocks. J Prosthet Dent 2015; 114: 98-102.

6) Guess PC, Kulis A, Witkowski S, Wolkewitz M, Zhang Y, Strub JR. Shear bond strengths between different zirconia cores and veneering ceramics and their susceptibility to thermocycling. Dent Mater 2008; 24: 1556-1567.

7) Vult von Steyern P, Carlson P, Nilner K. All-ceramic fixed 
partial dentures designed according to the DC-Zirkon technique. A 2-year clinical study. J Oral Rehabil 2005; 32: 180-187.

8) Raigrodski AJ, Chiche GJ, Potiket N, Hochstedler JL, Mohamed SE, Billiot S, Mercante DE. The efficacy of posterior three-unit zirconium-oxide-based ceramic fixed partial dental prostheses: a prospective clinical pilot study. J Prosthet Dent 2006; 96: 237-244

9) Abd El-Ghany OS, Sherief AH. Zirconia based ceramics, some clinical and biological aspects: Review. Future Dent J 2016; 2 : 55-64.

10) Flanders LA, Quinn JB, Wilson OC Jr, Lloyd IK. Scratch hardness and chipping of dental ceramics under different environments. Dent Mater 2003; 19: 716-724.

11) Aboushelib MN, Kleverlaan CJ, Feilzer AJ. Effect of zirconia type on its bond strength with different veneer ceramics. J Prosthodont 2008; 17: 401-408.

12) Manicone PF, Rossi Iommetti P, Raffaelli L. An overview of zirconia ceramics: basic properties and clinical applications. J Dent 2007; 35: 819-826.

13) Fischer J, Grohmann P, Stawarczyk B. Effect of zirconia surface treatments on the shear strength of zirconia/veneering ceramic composites. Dent Mater J 2008; 27: 448-454.

14) Fischer J, Stawarczyk B, Sailer I, Hammerle CH. Shear bond strength between veneering ceramics and ceria-stabilized zirconia/alumina. J Prosthet Dent 2010; 103: 267-274.

15) Mosharraf R, Rismanchian M, Savabi O, Ashtiani AH. Influence of surface modification techniques on shear bond strength between different zirconia cores and veneering ceramics. J Adv Prosthodont 2011; 3: 221-228.

16) Kim HJ, Lim HP, Park YJ, Vang MS. Effect of zirconia surface treatments on the shear bond strength of veneering ceramic. J Prosthet Dent 2011; 105: 315-322.

17) Liu D, Matinlinna JP, Tsoi JK, Pow EH, Miyazaki T, Shibata Y, Kan CW. A new modified laser pretreatment for porcelain zirconia bonding. Dent Mater 2013; 29: 559-565.

18) He M, Zhang Z, Zheng D, Ding N, Liu Y. Effect of sandblasting on surface roughness of zirconia-based ceramics and shear bond strength of veneering porcelain. Dent Mater J 2014; 33 : 778-785.

19) DeHoff PH, Anusavice KJ, Wang Z. Three-dimensional finite element analysis of the shear bond test. Dent Mater 1995; 11: 126-131

20) Versluis A, Tantbirojn D, Douglas WH. Why do Shear Bond Tests Pull Out Dentin? J Dent Res 1997; 76: 1298-1307.

21) Rasmussen ST. Analysis of dental shear bond strength tests, shear or tensile? Int J Adhes Adhes 1996; 16: 147-154.

22) Van Noort R, Noroozi S, Howard IC, Cardew G. A critique of bond strength measurements. J Dent 1989; 17: 61-67.

23) Van Meerbeek B, Peumans M, Poitevin A, Mine A, Van Ende A, Neves A, De Munck J. Relationship between bond-strength tests and clinical outcomes. Dent Mater 2010; 26: e100-e121.

24) Cheetham JJ, Palamara JE, Tyas MJ, Burrow MF. A comparison of the micro-shear bond strength and failure mode of non-enclosed and mold-enclosed luting cements bonded to metal. Dent Mater J 2013; 32: 896-905.

25) Jin XZ, Homaei E, Matinlinna JP, Tsoi JK. A new concept and finite-element study on dental bond strength tests. Dent Mater 2016; 32: e238-250.

26) Cheetham JJ, Palamara JE, Tyas MJ, Burrow MF. A comparison of the shear bond strength and failure mode to metals of unsupported and supported luting cement specimens. J Adhes Dent 2014; 16: 251-260.

27) Ban S. Reliability and properties of core materials for allceramic dental restorations. Jpn Dent Sci Rev 2008; 44: 3-21.

28) Wang G, Zhang S, Bian C, Kong H. Interface toughness of a zirconia-veneer system and the effect of a liner application. J Prosthet Dent 2014; 112: 576-583.
29) Aboushelib MN, Kleverlaan CJ, Feilzer AJ. Microtensile bond strength of different components of core veneered allceramic restorations. Part II: Zirconia veneering ceramics. Dent Mater 2006; 22: 857-863.

30) Tada K, Sato T, Yoshinari M. Influence of surface treatment on bond strength of veneering ceramics fused to zirconia. Dent Mater J 2012; 31: 287-296.

31) Tuncel İ, Özat P, Eroğlu E. Effects of coloring procedures on zirconia/veneer ceramics bond strength. J Adv Prosthodont 2014; 6: 451-455.

32) Shah K, Holloway JA, Denry IL. Effect of coloring with various metal oxides on the microstructure, color, and flexural strength of 3Y-TZP. J Biomed Mater Res B Appl Biomater 2008; 87: 329-337.

33) Ban S, Suzuki T, Yoshihara K, Sasaki k, Kawai T, Kono H. Effect of coloring on mechanical properties of dental zirconia. J Med Biol Eng 2014; 34: 24-29.

34) Kuroda S, Shinya A, Yokoyama D, Gomi H, Shinya A. Effects of coloring agents applied during sintering on bending strength and hardness of zirconia ceramics. Dent Mater J 2013; 32: 793-800.

35) Nakamura T, Wakabayashi K, Zaima C, Nishida H, Kinuta S, Yatani H. Tensile bond strength between tooth-colored porcelain and sandblasted zirconia framework. J Prosthodont Res 2009; 53: 116-119.

36) Teng J, Wang H, Liao Y, Liang X. Evaluation of a conditioning method to improve core-veneer bond strength of zirconia restorations. J Prosthet Dent 2012; 107: 380-387.

37) Ozkurt Z, Kazazoglu E, Unal A. In vitro evaluation of shear bond strength of veneering ceramics to zirconia. Dent Mater J 2010; 29: 138-146.

38) Oguri T, Tamaki Y, Hotta Y, Miyazaki T. Effects of a convenient silica-coating treatment on shear bond strengths of porcelain veneers on zirconia-based ceramics. Dent Mater J 2012; 31: 788-796.

39) Al-Dohan HM, Yaman P, Dennison JB, Razzoog ME, Lang BR. Shear strength of core-veneer interface in bi-layered ceramics. J Prosthet Dent 2004; 91: 349-355.

40) Aktas G, Sahin E, Vallittu P, Ozcan M, Lassila L. Effect of colouring green stage zirconia on the adhesion of veneering ceramics with different thermal expansion coefficients. Int $J$ Oral Sci 2013; 5: 236-241.

41) Choi BK, Han JS, Yang JH, Lee JB, Kim SH. Shear bond strength of veneering porcelain to zirconia and metal cores. J Adv Prosthodont 2009; 1: 129-135.

42) Vidotti HA, Pereira JR, Insaurralde E, de Almeida AL, do Valle AL. Thermo and mechanical cycling and veneering method do not influence Y-TZP core/veneer interface bond strength. J Dent 2013; 41: 307-312.

43) Nishigori A, Yoshida T, Bottino MC, Platt JA. Influence of zirconia surface treatment on veneering porcelain shear bond strength after cyclic loading. J Prosthet Dent 2014; 112: 13921398.

44) Matsumoto N, Yoshinari M, Takemoto S, Hattori M, Kawada E, Oda Y. Effect of intermediate ceramics and firing temperature on bond strength between tetragonal zirconia polycrystal and veneering ceramics. Dent Mater J 2013; 32: 734-743.

45) Hammad IA, Talic YF. Designs of bond strength tests for metal-ceramic complexes: review of the literature. J Prosthet Dent 1996; 75: 602-608.

46) Sim JY, Lee WS, Kim JH, Kim HY, Kim WC. Evaluation of shear bond strength of veneering ceramics and zirconia fabricated by the digital veneering method. J Prosthodont Res 2016; 60: 106-113.

47) ISO 9693-2:2016 Dentistry —Compatibility testing- Part 2: Ceramic-ceramic systems. International Organization for Strandardization, Geneva, Switzerland. 